\title{
Dysregulation of Signal Transduction Pathways as a Potential Mechanism of Nervous System Alterations in HIV-1 gp120 Transgenic Mice and Humans with HIV-1 Encephalitis
}

\author{
Tony Wyss-Coray, ${ }^{\star}$ Eliezer Masliah, ${ }^{\ddagger}$ Stephanie M. Toggas, ${ }^{\S}$ Edward M. Rockenstein, ${ }^{\star}$ Madelyne J. Brooker, $\$$ \\ Ho Suk Lee,,$^{\S}$ and Lennart Mucke ${ }^{\star \S}$ \\ *The Gladstone Molecular Neurobiology Program and Department of Neurology, University of California, San Francisco, California \\ 94141-9100; ${ }^{\ddagger}$ Departments of Neurosciences and Pathology, University of California San Diego, La Jolla, California 92093-0624; and \\ ${ }^{\S}$ Department of Neuropharmacology, The Scripps Research Institiute, La Jolla, California 92037
}

\begin{abstract}
HIV-1 associated central nervous system (CNS) disease involves neuronal damage and prominent reactive astrocytosis, the latter characterized by strong upregulation of the glial fibrillary acidic protein (GFAP) in astrocytes. Similar alterations are found in transgenic mice expressing the HIV-1 envelope protein gp120 in the CNS. Because alterations of astrocyte functions could contribute to neuronal impairment, we compared brains of gp120 transgenic mice and gp120-transfected C6 astrocytoma cells with controls and found that gp120 induced a prominent elevation of steady state GFAP mRNA levels, primarily due to transcript stabilization. Increased levels of GFAP mRNA were also found in nontransfected C6 cells exposed to recombinant gp120. Exposure of C6 cells or primary mouse astrocytes to soluble gp120 led to activation of PKC as indicated by redistribution and increase in PKC immunoreactivity at the single cell level. gp120 effects were diminished by inhibitors of protein kinase C (PKC) but not inhibitors of protein kinase A. PKC activity was upmodulated in gp120-transfected C6 cells and in the CNS of gp120 transgenic mice. Further, brain tissue from patients with HIV-1 encephalitis and from gp120 transgenic mice showed increased PKC immunoreactivity. Taken together, these results indicate that gp120-induced increases in PKC activity may contribute to the gliosis seen in gp120 transgenic mice as well as in HIV1-infected humans and raise the question of whether dysregulation of signal transduction pathways represents a general mechanism of $\mathrm{HIV}$-associated pathogenesis. $(\mathrm{J}$. Clin. Invest. 1996. 97:789-798.) Key words: AIDS dementia complex • glial fibrillary acidic protein • astrocytes $\bullet$ messenger RNA • signal transduction
\end{abstract}

Preliminary results of this study were presented in abstract form at the Clinical Research Meeting in San Diego on 5 May 1995.

Address correspondence to L. Mucke, Gladstone Molecular Neurobiology Program, PO Box 419100, San Francisco, CA 94141-9100. Phone: 415-826-7500; FAX: 415-285-5632; E-mail: Lennart_Mucke@ quickmail.ucsf.edu

Received for publication 6 June 1995 and accepted in revised form 10 November 1995.

J. Clin. Invest.

(C) The American Society for Clinical Investigation, Inc.

0021-9738/96/02/0789/10 \$2.00

Volume 97, Number 3, February 1996, 789-798

\section{Introduction}

HIV-1 continues to spread at a rapid rate, and the clinical manifestations associated with this viral infection present increasing medical and socioeconomic problems. A significant proportion of HIV-1-infected people develop severe immunodeficiency as well as impairments of the central nervous system (CNS) that can culminate in dementia, paralysis, and death (for review see reference 1). Notably, virus-induced cytolysis of immune and CNS cells does not appear to be the primary pathogenic process responsible for these disease manifestations. Instead, evidence is accumulating that HIV-1 may induce disease indirectly by altering the expression of host factors, thereby dysregulating the intricate molecular and cellular networks that control the immune system and the CNS (1-7).

Recently, we demonstrated that expression of the HIV-1 envelope glycoprotein gp120 in brains of transgenic $(\mathrm{tg})^{1}$ mice induces a spectrum of CNS alterations (8) which closely resemble neuropathological abnormalities found in patients with AIDS dementia complex (1) including reactive astrocytosis and microgliosis, formation of microglial nodules, loss of neuronal subpopulations, dropout of presynaptic terminals, and widespread vacuolar degeneration of neuronal dendrites. Subsequent experiments in gp120 tg mice have focused on the dissection of the pathogenetic processes that may underlie gp120induced neurotoxicity in this model. The current study aimed to determine how gp120 expression affects astrocytes and induces reactive astrocytosis, an early and prominent neuropathological alteration in both gp120 tg mice (8) and HIV-1infected humans (9-12). Astrocytes are macroglial CNS cells that provide crucial support for neurons and oligodendrocytes through such diverse functions as the production of trophic factors and the elimination of toxins (for reviews see references 13 and 14). Increased expression of glial fibrillary acidic protein (GFAP) is a characteristic marker of astrocyte activation/reactive astrocytosis. The exact mechanisms underlying this response remain unknown; however, reactive astrocytosis features prominently in a variety of CNS infections (13-15). The absence of astrocytosis in mice with GFAP-driven astroglial expression of Escherichia coli $\beta$-galactosidase (8), human $\alpha 1$-antichymotrypsin (8), mouse MHC class I (16), or human amyloid precursor protein (17) indicates that the prominent in-

1. Abbreviations used in this paper: ACT, human $\alpha 1$-antichymotrypsin; APP, amyloid precursor protein; CMV, cytomegalovirus; GAPDH, glyceraldehyde-3-phosphate dehydrogenase; GFAP, glial fibrillary acidic protein; GS, glutamine synthetase; HIVE, HIV-1 encephalitis; PK, protein kinase; RPA, RNase protection assay; tg, transgenic. 
crease in astroglial GFAP expression in gp120 tg mice does not represent a nonspecific consequence of overexpressing proteins in astrocytes in vivo.

Here we show that HIV-1 gp120 induces a prominent elevation of steady state GFAP mRNA levels in astroglial cells both in vitro and in vivo ${ }^{2}$ and that this is primarily due to stabilization of GFAP transcripts rather than to increased transcription of the GFAP gene. In addition, we provide evidence that this abnormal stabilization of the GFAP message is mediated by gp120-induced stimulation of protein kinase $\mathrm{C}$ (PKC) activity and that increased $\mathrm{PKC}$ immunoreactivity is present in postmortem brain tissue from HIV-1-infected humans.

\section{Methods}

Animals. Heterozygous tg $\mathrm{B} 6 \times \mathrm{SJL}$ mice expressing $\mathrm{HIV}_{\mathrm{LAV}}$-gp120, E. coli $\beta$-galactosidase (lacZ) or human $\alpha 1$-antichymotrypsin (ACT) in astrocytes were from the previously established GFAP-gp120 lines 2, 10, and 16 (8), the GFAP-lacZ line C-445-16 (18), and the GFAPACT line $13(8,19)$. Transgene expression in these models is directed by a modified GFAP gene. Non-tg littermates served as controls. Bigenic gp120/ACT mice were generated essentially as described (20). Animal care was in accordance with institutional guidelines. For transcardial perfusions, mice were anesthetized by intraperitoneal injection of $0.5-0.7 \mathrm{ml}$ of $3.8 \%$ chloral hydrate solution.

Cell culture and generation of stable transfectants. Rat C6 glioma cells (CCL 107; American Type Culture Collection, Rockville, MD) were grown in a humidified tissue culture incubator at $37^{\circ} \mathrm{C}$ and $5 \%$ $\mathrm{CO}_{2}$. Regular media consisted of DME containing $10 \%$ fetal bovine serum, $2 \mathrm{mM}$ L-glutamine, penicillin $(100 \mathrm{U} / \mathrm{ml})$, and streptomycin $(100 \mu \mathrm{g} / \mathrm{ml})$; selection media consisted of regular media plus Geneticin $(600 \mu \mathrm{g} / \mathrm{ml})$ (GIBCO-BRL, Gaithersburg, MD). Cells were transfected at $30-50 \%$ confluency with $10 \mu \mathrm{g}$ GFAP-gp120 (8), GFAPlacZ (C-445) (18), or GFAP-ACT $(8,19)$, in a modified pGEMEX-2 plasmid, in combination with $1 \mu \mathrm{g}$ pSV2-neo (CLONTECH, Palo Alto, CA) using Lipofectin (GIBCO-BRL) per manufacturer's recommendations. Similarly, C6 cells were transfected with gp120-coding sequences (NotI segment of GFAP-gp120 [8]) placed downstream of the cytomegalovirus (CMV) promoter of $\mathrm{pCMV} \beta$ (CLONTECH); the lacZ element of the latter plasmid was deleted. After $5 \mathrm{~h}$ of exposure to Lipofectin/DNA mixtures in Optimem (GIBCO-BRL) and subsequent incubation in regular media for $48 \mathrm{~h}$, cells were maintained in selection media (exchanged twice a week). After $2 \mathrm{wk}$, wellisolated drug-resistant colonies were transferred into individual wells of 24-well culture plates, amplified, and stored in liquid nitrogen. Transgene-expressing cell lines were identified by RNA analysis (see below). For each construct, experimental results were confirmed in two to three different stably transfected expressor cell lines. Experiments were carried out after passages 3-10 (after recovery of cells from frozen stocks); during this time, transgene expression levels in individual cell lines remained stable as determined by RNA analysis in RNase protection assays (see below).

Primary mouse astrocytes were isolated from newborn non-tg mice as described (15) and cultured for up to $4 \mathrm{wk}$ in regular medium.

For experiments, $100 \%$ confluent cells (maintained in selection medium) were harvested and seeded at $2 \times 10^{6}$ cells per Petri dish $\left(100 \mathrm{~mm}^{2}\right)$ in $10 \mathrm{ml}$ or at $4 \times 10^{6}$ cells per T175 flask in $40 \mathrm{ml}$ of regular medium in the absence of Geneticin. All subsequent steps were carried out in this medium. After $2 \mathrm{~d}$, when cells reached confluency, cells were either washed with $0.9 \%$ saline and harvested using a cell scraper for nuclear run-off or PKC assays (see below) or incubated further after replacement of half the medium with fresh medium. Af-

2. Throughout this text, in vitro refers to cells grown in culture and in vivo refers to living animals or humans. ter an additional 2-d incubation, the following inhibitors (or vehicle alone) were added directly to the culture media $\left(\leq 10^{-3} \mathrm{vol} / \mathrm{vol}\right)$ without addition of fresh media (to avoid media exchange-induced decreases in GFAP mRNA levels [21]): actinomycin D, phorbol 12myristate 13-acetate (PMA) (in ethanol), $\mathrm{H} 7$ or $\mathrm{HA} 1004\left(\right.$ in $\mathrm{H}_{2} \mathrm{O}$ ), or Calphostin C (in DMSO) (all reagents from Calbiochem-Novabiochem, San Diego, CA). In experiments with Calphostin C, cell cultures were exposed to a white light source during the 24-h incubation period as described elsewhere (22). In some experiments, cells were exposed to recombinant (baculovirus-expressed) $\mathrm{HIV}_{\text {IIIB }}-\mathrm{gp} 120$ (AgMed, Bedford, MA). After incubation for an additional 1-48 h, cells were harvested for analysis.

RNA extraction and analysis. Total RNA was isolated from normal saline flush-perfused, snap-frozen whole hemibrains and from pellets of 3-5 × $10^{6} \mathrm{C} 6$ cells using TRI- and TRI-LS reagents (Molecular Research Center, Inc., Cincinnati, OH), respectively, per manufacturer's recommendations. RNA was analyzed using solution hybridization RNase protection assays (RPAs) as described (23). The following ${ }^{32} \mathrm{P}$-labeled antisense riboprobes were used to identify specific mRNAs (protected sequences in parentheses): (1) gp120 (nucleotides 6384-6730 of HIV LAV [GenBank accession No. K03455]); (2) ACT (nucleotides 200-380 of ACT cDNA [GenBank accession No. K01500]); (3) lacZ (nucleotides 2355-2555 of pCMV $\beta$ [GenBank accession No. U02451]); (4) GFAP (nucleotides 818-1027 of mouse GFAP cDNA [GenBank accession No. K01347]); (5) GS (nucleotides 937-1234 of mouse glutamine synthetase [GS] cDNA [24]); (6) $\beta$-actin (nucleotides $480-559$ of mouse $\beta$-actin cDNA [GenBank accession No. M18194]); and (7) GAPDH (nucleotides 714-828 of rat glutaraldehyde-3-phosphate dehydrogenase (GAPDH) cDNA [GenBank accession No. M17701]). Probes 1 through 3 are transgene specific; probes 4 through 7 protect endogenous gene products of both mouse and rat. Sample RNA hybridized to ${ }^{32} \mathrm{P}$-labeled antisense riboprobes was digested with $300 \mathrm{U} / \mathrm{ml}$ RNase T1 (GIBCO-BRL) plus 0.5 $\mu \mathrm{g} / \mathrm{ml}$ RNase A (Sigma Immunochemicals, St. Louis, MO) in $100 \mu \mathrm{l}$ digestion buffer followed by protein digestion with $10 \mathrm{mg} / \mathrm{ml}$ proteinase K (Sigma Immunochemicals) as described (23). Subsequently, RNA was isolated with $4 \mathrm{M}$ guanidine thiocyanate and precipitated in isopropanol. Samples were separated on 5\% acrylamide/8 M urea TBE gels and dried gels were exposed to XAR film (Kodak, Rochester, NY). Levels of specific transcripts were estimated by quantitating probe-specific signals with a PhosphorImager (Molecular Dynamics, Sunnyvale, CA); $\beta$-actin and GAPDH signals were used to correct for differences in RNA content/loading as described (18). A riboprobe spanning the junction of GFAP exons 5 and 6 (nucleotides 866-1136 of rat GFAP cDNA [GenBank accession No. U03700]) protected only one mRNA species, its size ( $270 \mathrm{bp}$ ) being consistent with spliced mRNA (not shown). This indicates that our RNA preparation contained no or only insignificant amounts of heteronuclear RNA.

Nuclear run-off assays. Assays were performed essentially as described (25), with some modifications: nuclei were isolated from $2-5 \times$ $10^{7}$ stably transfected C6 cells or mock-transfected cells and incubated for in vitro transcription using $100 \mu \mathrm{Ci}\left[\alpha-{ }^{32} \mathrm{P}\right] \mathrm{UTP}(800 \mathrm{Ci}$ $\mathrm{mmol}^{-1}$ ) per reaction. Labeled RNA was isolated using TRI-LS reagent (Molecular Research Center, Inc.). Segments of GAPDH (nucleotides 211-969; see above for GenBank accession Nos.), GFAP (nucleotides 139-1136), ACT (nucleotides 200-1033), and gp120 (nucleotides 6384-7166) coding sequences were generated by PCR using cloned cDNAs as templates. $5 \mu \mathrm{g}$ of each PCR product was denatured and applied to Nytran membranes (Schleicher \& Schuell, Keene, NH) using a slot blot apparatus (Schleicher \& Schuell). $5 \times$ $10^{6} \mathrm{cpm}$ of ${ }^{32} \mathrm{P}$-labeled transcripts were hybridized with immobilized DNAs at $65^{\circ} \mathrm{C}$ overnight in $1 \mathrm{ml}$ hybridization buffer. Membranes were then washed and exposed to Kodak XAR film for 3-10 d. Radioactive signals were quantitated with a PhosphorImager (Molecular Dynamics).

$P K C$. Total cellular PKC activity in mouse brains and C6 cells was measured using a PKC assay kit (GIBCO-BRL) per manufacturer's instructions. In brief, normal saline flush-perfused brain tis- 
sues (either entire hemibrains or tissue blocks consisting of cortex, hippocampus, and olfactory bulb) or pellets of $2-5 \times 10^{7}$ stably transfected C6 cells were homogenized in Triton X-100-containing extraction buffer ( $20 \mathrm{mM}$ Tris, pH 7.5, $0.5 \mathrm{mM}$ EDTA, $0.5 \mathrm{mM}$ EGTA, $0.5 \%$ Triton X-100, $25 \mu \mathrm{g} / \mathrm{ml}$ aprotinin and leupeptin) using a VirtisShear tissue homogenizer (Virtis Co., Gardiner, NY) and homogenates were incubated on ice for $30 \mathrm{~min}$. After removing cellular debris by 2 min of centrifugation at $15,000 \mathrm{~g}$, the supernatant containing activated PKC released from membranes by the detergent treatment was recovered, and PKC was partially purified by DEAE-cellulose column chromatography as described (26). The protein concentration in DEAE column eluates was determined by Bradford's method using a commercial protein assay kit (Bio Rad Laboratories, Hercules, CA). Specific PKC activity in the eluates were determined by measuring the difference between the phosphorylation of a PKC-specific substrate, incubated with different aliquots of each sample in the presence versus absence of a specific PKC inhibitor (27). The PKCspecific substrate was a synthetic peptide from myelin basic protein (amino acids 4-14) with an acetylated $\mathrm{NH}_{2}$-terminal glutamine, and the specific inhibitor was a pseudosubstrate peptide (PKC amino acids 19-36) which competes with normal substrate at the PKC substrate binding site. The reaction mixtures containing enzyme, $\left[\gamma^{-32} \mathrm{P}\right]$ ATP $\left(3,000 \mathrm{Ci} \mathrm{mmol}^{-1}\right)$, substrate peptide, and either inhibitor or buffer were incubated at $30^{\circ} \mathrm{C}$ for $5 \mathrm{~min}$ and then spotted on phosphocellulose paper disks. Unbound label was removed by washing with $1 \%$ phosphoric acid followed by $\mathrm{H}_{2} \mathrm{O}$, and radioactivity incorporated into substrate was measured in a beta counter after immersion of the paper disks in scintillation fluid. Samples were assayed in duplicate at two serial dilutions in the presence or absence of inhibitor peptide, and PKC activity was normalized to the amount of protein applied to DEAE columns.

Immunocytochemical analysis and microdensitometry. Paraformaldehyde-fixed tissue blocks from the frontal cortex of patients with HIV-1 encephalitis (HIVE) and uninfected age-matched controls were obtained postmortem and serially sectioned at $40 \mu \mathrm{m}$ with a Vibratome 2000 (Technical Products International Inc., St. Louis, MO) as described (28). The presence of HIVE was established by demonstrating HIV-1 gp41 antigen immunoreactivity in brain sections that showed typical neuropathological alterations (28). Brains of GFAPgp120 tg and non-tg mice were also fixed and sectioned as described (8). Sections from human or murine cases were incubated overnight at $4{ }^{\circ} \mathrm{C}$ with a rabbit polyclonal antibody against GFAP (BioGenex Labs, San Ramon, CA) at 1:750 or with a mouse monoclonal antibody against PKC (clone MC5; Amersham Corp., Arlington Heights, IL) at $10 \mu \mathrm{g} / \mathrm{ml}$. Binding of primary antibodies was detected with species-matched biotinylated secondary antibodies and revealed with avidin-biotin peroxidase kits (Vector Labs Inc., Burlingame, CA). Before further evaluation, sections were blind coded to ensure objective assessment. Codes were not broken until the analysis was complete. Relative levels of PKC or GFAP immunoreactivity were determined microdensitometrically using the Quantimet 570C (Leica Inc., Arcadia, CA) as described (8) in human cortex and murine frontoparietal (i.e., frontal plus parietal) cortex. Corrected optical density values were obtained by subtracting background optical densities (from sections immunostained without primary antibody). Significance of differences between average optical densities was assessed by unpaired, two-tailed Student's $t$ test.

Double immunolabeling and laser scanning confocal microscopy (LSCM). Double immunolabeling studies to determine the colocalization between PKC (MC5 monoclonal antibody) and astroglial cell markers (GFAP polyclonal antibody) were performed as described $(28,29)$. The MC5 antibody was raised against rat brain PKC and recognizes $\alpha$ and $\beta$ but not $\gamma$ isoforms of PKC. Primary astrocytes or C6 cells were seeded at $1 \times 10^{5}$ cells onto poly-L-lysine-coated (Sigma Immunochemicals) glass cover slips (Fisher Scientific, Tustin, CA) and cultured for $24 \mathrm{~h}$ in regular medium before they were stimulated with different concentrations of recombinant gp120, PMA, or vehicle alone for $1 \mathrm{~h}$. Cells were then fixed with $4 \%$ paraformaldehyde and rinsed with PBS for immunostaining. Vibratome sections $(40 \mu \mathrm{m}$ thick) were obtained postmortem from the frontal cortex of AIDS patients with HIVE (as defined in reference 28) $(n=5)$, AIDS patients with CMV encephalitis but without detectable HIV antigen in the CNS $(n=5)$, and HIV-positive, age-matched control individuals without CNS alterations $(n=5)$. For each case, routine neuropathological examination was performed on hematoxylin and eosinstained brain sections. All cases selected for this study showed no evidence for either opportunistic CNS infections, including cryptococcosis, toxoplasmosis, and herpes simplex virus encephalitis, or lymphomas. HIVE was diagnosed based on the criteria in reference 28 . The cases with CMV encephalitis and controls without CNS alterations included in this study displayed no gp41 immunoreactivity in their brains and lacked the neuropathological characteristics of HIVE. Cell cultures and tissue sections were double-immunolabeled with the PKC and GFAP antibodies described above, then incubated with a mixture of FITC-conjugated horse anti-mouse IgG (1:75; Vector Labs Inc.) and Cy 5 D-conjugated goat anti-rabbit IgG (1:150; Jackson ImmunoResearch, West Grove, PA), transferred to SuperFrost slides (Fisher Scientific), mounted with antifading mounting medium (Vector Labs Inc.), and analyzed with the Bio-Rad MRC-1024 LSCM

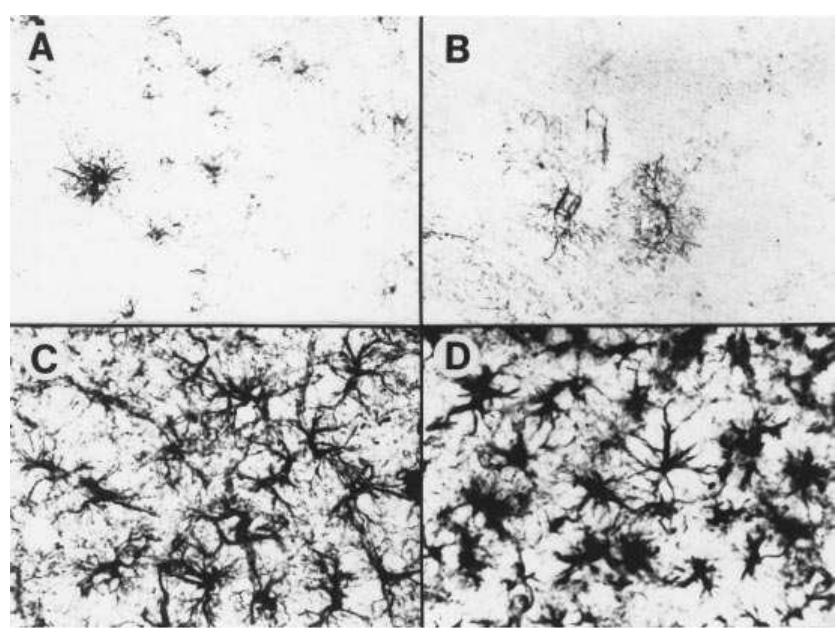

E

$\mathbf{F}$
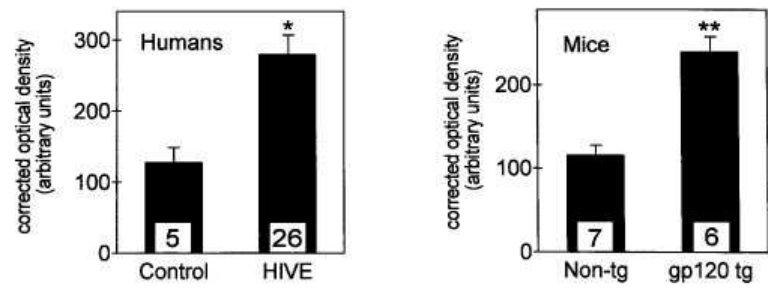

Figure 1. Increased GFAP immunoreactivity in brains of humans with HIVE and tg mice with cerebral expression of HIV-1 gp120. Sections of human neocortices obtained postmortem from an uninfected control $(A)$ and from a patient with HIVE $(C)$ as well as of murine neocortices from a non-tg $(B)$ and a gp120 $\operatorname{tg}(D$; high expressor line 2) mouse were immunolabeled with an antibody against the astroglial marker GFAP. Note the prominent astrocytosis, reflected by an increased number of strongly GFAP-immunoreactive astrocytes of hypertrophied morphology, in the HIV-1-infected human $(C)$ and the gp120 tg mouse $(D)$. Quantitative microdensitometric analysis of such immunostained sections (three per case) revealed significant increases in GFAP immunoreactivity in HIVE brains compared with uninfected controls $(E)$ and in brains from gp120 tg mice compared with non-tg controls $(F)$. Columns represent means \pm SEM; the number of cases analyzed is indicated at the bottom of each column $\left({ }^{*} P<\right.$ 0.01 , $* * P<0.001$, by unpaired two-tailed Student's $t$ test). 
A

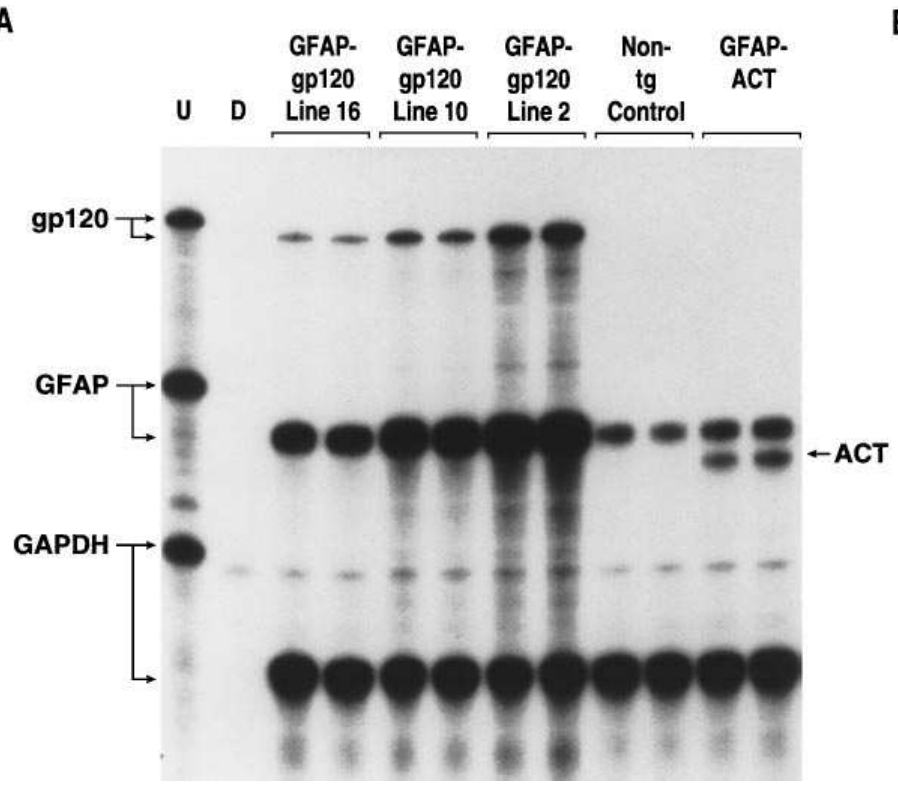

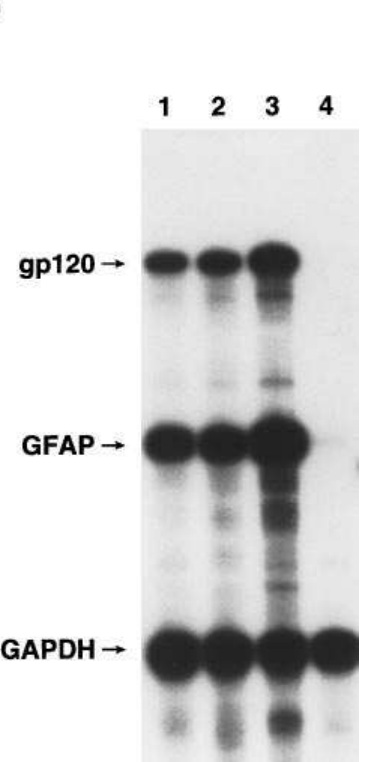

Figure 2. Increased steady state GFAP mRNA levels in gp120 tg brains and C6-gp120 astrocytoma cells. (A) Brain RNA from gp120 $\operatorname{tg}$ mice (three distinct lines) and controls (non-tg and ACT tg mice) ( $n=2$ /group) was analyzed by RPA using antisense riboprobes for gp120, GFAP, ACT, and GAPDH. Lane $U$ shows signals of undigested radiolabeled probes (tRNA but no RNase added); the other lanes contained the same riboprobes plus either tRNA (lane $D$; no specific hybridization) or brain RNA samples, digested with RNase. The lower branch of the split arrows on the left and the ACT arrow on the right indicate the expected size of protected probe/mRNA hybrids after digestion of noncomplementary probe sequences (vector-

derived) and transcripts. GAPDH signals were used as a control for RNA content/loading. (B) RNA isolated from three lines of C6-gp120 cells showing different levels of gp120 mRNA expression (lanes 1-3) and from C6-neo control cells (lane 4) were analyzed as described above. To reveal differences in GFAP mRNA levels among these different cell lines, the gel was exposed for only 4 h. Because C6-neo cells express GFAP mRNA at 20- to 90-fold lower levels than C6-gp120 cells, only a weak signal is seen in these control cells (lane 4). Note the positive correlation between gp120 and GFAP mRNA levels across different lines of gp120 tg mice and C6-gp120-transfected cells.

mounted on an Axiovert Zeiss microscope with a $63 \times$ oil immersion objective (NA 1.4). This system permits the simultaneous analysis of double-immunolabeled samples in the same optical plane as well as the semiquantitative assessment of levels of immunoreactivity by determining pixel intensity in digitized serial optical sections obtained within a linear range (30). For each stimulated and control primary astrocyte culture, five fields (each $100 \times 70 \mu \mathrm{m}^{2}$ ) containing two to three astrocytes per field were imaged. Double-immunolabeling and imaging was done on two coverslips per condition in two independent experiments. For double-immunolabeled human brain sections, five fields (each $100 \times 70 \mu \mathrm{m}^{2}$ ) were imaged per case with each field containing 2-25 astrocytes. Pixel intensity measurements were analyzed statistically using the GraphPad InStat software.

\section{Results}

Astrocytes in brains of HIV-1-infected humans and gp120 tg mice. Brains of humans with HIVE and of mice expressing HIV-1 gp120 in the CNS showed a prominent and widespread increase in the number of astrocytes expressing GFAP compared with normal uninfected/non-tg control brains (Fig. 1). Consistent with a state of activation, astrocytes in HIVE cases and gp120 tg mice displayed a hypertrophied morphology (Fig. $1, C$ and $D$ ). This astrocytosis was reflected in statistically significant increases in GFAP immunoreactivity when brain sections from HIVE cases and gp120 tg mice were compared quantitatively with brain sections from uninfected/non-tg controls (Fig. 1, $E$ and $F$ ).

gp120 induced an increase in GFAP $m R N A$ steady state levels in vivo and in vitro. Quantitation of mRNA steady state levels by RPA revealed substantial elevations of GFAP mRNA levels in brains of gp120 tg mice compared with levels found in non-tg mice or tg controls that express ACT (Fig. 2 $A$ ) or $E$. coli $\beta$-galactosidase (lacZ) (not shown) from the same GFAP promoter, confirming results obtained by Northern blot analysis (8). Across different lines of gp120 tg mice, elevated GFAP mRNA levels correlated directly with levels of gp120 mRNA expression (Fig. $2 A$ ). PhosphorImager quantitation of signals shown in Fig. $2 A$ revealed the following GFAP to GAPDH mRNA ratios (two mice per group): non-tg, 11 and 16; GFAP-gp120 line 16, 41 and 46; GFAP-gp120 line 10, 109 and 123; GFAP-gp120 line 2, 243 and 246; GFAP-ACT, 15 and 15 .

To further dissect the mechanisms that underlie the gp120induced increase in GFAP mRNA levels, the in vivo analysis of gp120 tg mice was complemented with an astroglial in vitro model. Rat C6 astrocytoma cells, cotransfected stably with pSV2-neo and a plasmid containing the same GFAP-gp120 fusion gene that was used to establish gp120 tg mice, had been shown previously to secrete immunoprecipitable gp120 into the culture media (8). The amount of gp120 secreted by three distinct gp120 expressor lines (low, intermediate, and high) was found to correlate directly with their levels of gp120 mRNA expression (not shown). These C6-gp120 cell lines were compared with controls consisting of C6 cells stably transfected with $(a)$ the pSV2-neo plasmid alone (C6-neo; i.e., mock-transfected); (b) GFAP-lacZ plus pSV2-neo (C6-lacZ); or (c) GFAP-ACT plus pSV2-neo (C6-ACT). Consistent with the results obtained in GFAP-gp120 tg mice, C6-gp120 cells expressed substantially higher levels of GFAP mRNA than mock-transfected C6 cells (Fig. 2 B) or C6 cells expressing other GFAP-driven transgenes (not shown). Across different lines of C6-gp120 cells, GFAP mRNA levels correlated directly with gp120 mRNA levels. Subsequent experiments were performed with the low expressor line (Fig. 2 B, lane 1 ) except where indicated otherwise. To exclude that GFAP sequences incorporated into the GFAP-gp120 transgene could directly or indirectly contribute to the increased GFAP message levels in C6-gp120 cells, C6 cells were stably transfected with a CMVgp120 fusion gene (C6-gp120*). These cells also showed sub- 

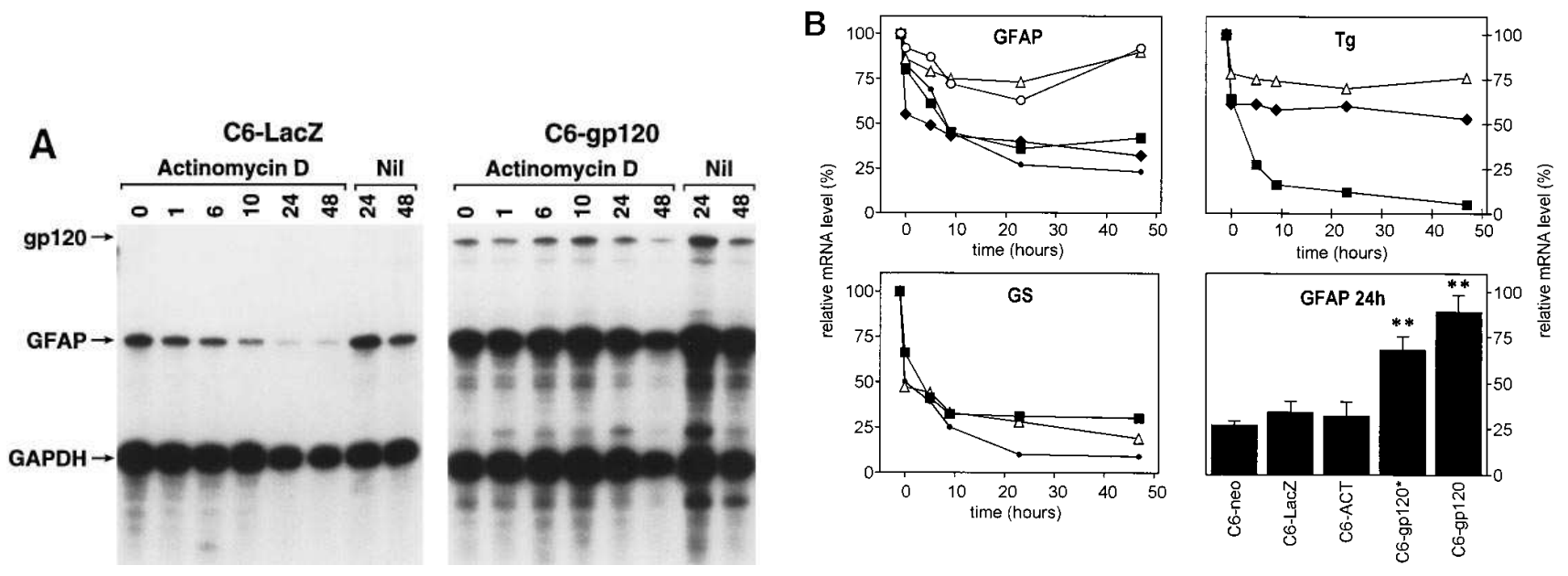

Figure 3. Increased GFAP mRNA stability in gp120-transfected C6 cells. RNA was isolated from C6-gp120 and control cells at different time points $(0-48 \mathrm{~h})$ after the addition of the transcription inhibitor actinomycin $\mathrm{D}(5 \mu \mathrm{g} / \mathrm{ml})$ or vehicle alone (Nil) and levels of mRNAs encoding gp120, GFAP, GS, lacZ, ACT, or GAPDH were determined by RPA, as described in Methods and Fig. 2. (A) Autoradiograph depicting representative hybridization signals (probes indicated on the left). (B) PhosphorImager quantitation of mRNAs encoding GFAP (top left), GS (bot-

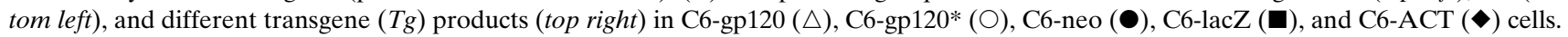
$X$-axis shows the time from addition of actinomycin D. $Y$-axis shows the relative mRNA levels (percentage) as compared with mRNA levels at time 0 (normalized to GAPDH mRNA levels). The increase in relative mRNA levels at the 24- and 48-h time points (top panels) is due to a relative decrease in GAPDH mRNA stability (see $A$ ). The bottom right panel provides a statistical analysis of results obtained from two (for C6ACT), three (C6-lacZ, C6-gp120*), or five (C6-neo, C6-gp120) independent experiments using different batches of cells; GFAP mRNA levels were measured $24 \mathrm{~h}$ after addition of actinomycin D and were expressed as a percentage of mRNA levels obtained at time 0 . Columns represent means \pm SEM. Note the significant stabilization of the GFAP message in cells transfected with either the CMV-gp120 (C6-gp120*) or the GFAPgp120 (C6-gp120) construct compared with C6-neo controls (**P $<0.01$ by Dunnett's multiple comparisons test). The C6-gp120* cells used in this experiment expressed slightly lower levels of gp120 mRNA than the C6-gp120 cells (not shown).

stantial increases in GFAP mRNA levels compared with those found in mock-transfected controls (Fig. $3 B$ ).

The gp120-induced increase in GFAP steady state $m R N A$ levels reflects message stabilization. To determine whether the gp120-induced increase in steady state GFAP mRNA levels was due to decreased decay or increased synthesis of GFAP transcripts, mRNA decay rates were determined after blockade of transcription, and mRNA synthesis was assessed independently in nuclear run-off experiments. RNA was isolated from C6-gp120, C6-gp120*, C6-neo, C6-lacZ, and C6-ACT cells at different time points after the addition of the transcription inhibitor actinomycin $\mathrm{D}$, and levels of mRNAs encoding GFAP, the astrocyte-specific enzyme GS, gp120, lacZ, ACT, or GAPDH were determined by RPA (Fig. 3). During $48 \mathrm{~h}$ after actinomycin D addition, GFAP mRNA levels in the different groups of control cells showed similar rates of decay, whereas GFAP mRNA levels in C6-gp120 and C6-gp120* cells showed much less decay (Fig. 3, $A$ and $B$ ). In contrast, GS mRNA levels showed similar rates of decay in C6-gp120 and control cells (Fig. 3 B). To determine whether gp120, in addition to stabilizing GFAP mRNA, also increases GFAP gene transcription, C6-gp120 and control cells were analyzed by nuclear run-off assay. In two independent experiments, nuclei isolated from C6-gp120 cells showed a relatively small increase in GFAP gene transcription compared with nuclei isolated from C6-neo cells (21 and 24\% increase over control levels, respectively; data not shown).

In brains of bigenic mice, gp120 induced a prominent increase in endogenous GFAP mRNA levels but not in the expression of GFAP-driven fusion genes. To determine whether the prominent increase in steady state GFAP mRNA levels in vivo was also due more to GFAP message stabilization than to increased transcription of the GFAP gene, we analyzed brains of $\mathrm{tg}$ mice. Because accurate measurements of transcriptional activity and mRNA stability are difficult to obtain in vivo, a bigenic approach was used to address this issue indirectly. Transgenic mice expressing gp120 alone or in combination with ACT were used to measure the influence of cerebral gp120 expression on levels of mRNAs derived from the endogenous GFAP gene and from the GFAP-ACT fusion gene, respectively. If gp120 increased transcription from the GFAP promoter, the steady state mRNA levels of ACT in gp120/ ACT bigenic mice would be expected to be increased (Fig. 4 A). In contrast, if gp120 stabilized GFAP mRNA, it would not necessarily stabilize ACT mRNA. To test these hypotheses, brain levels of mRNAs encoding endogenous GFAP, gp120, or ACT were determined by RPA in bigenic mice and compared with those in singly tg and non-tg littermate controls. gp120 singly tg mice and gp120/ACT bigenic mice showed similar elevations of GFAP mRNA levels over those found in non-tg mice and GFAP-ACT singly tg controls (Fig. $4 \mathrm{~B}$ ). In contrast, gp120 expression in bigenic mice failed to increase the expression of ACT (Fig. $4 \mathrm{~B}$ ). These in vivo results are consistent with our in vitro data which indicate that gp120induced increases in GFAP mRNA levels reflect primarily GFAP mRNA stabilization rather than increased transcription of the GFAP gene.

Inhibitors of PKC but not of PKA decreased the GFAP mRNA elevations found in C6-gp120 cells in a dose-dependent manner. It has been demonstrated that both PKC and PKA are involved in the posttranscriptional regulation of GFAP mRNA levels in astrocytoma cells and primary astrocytes (21, 


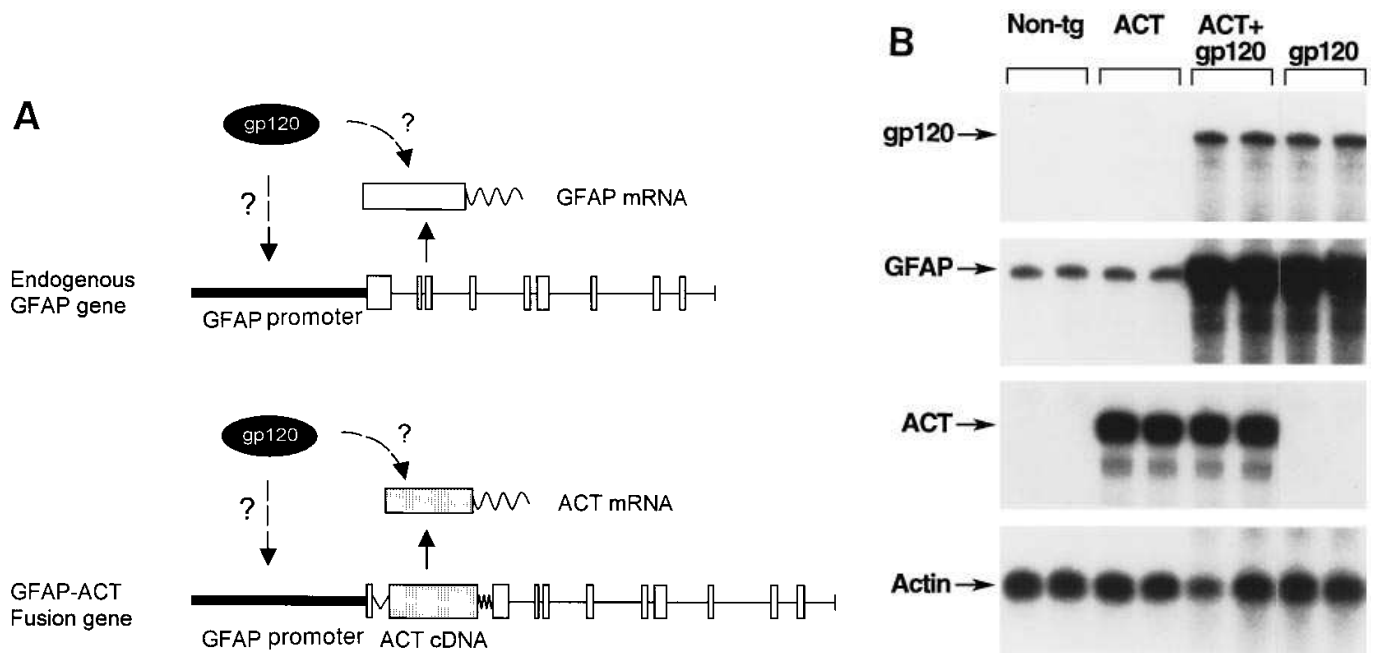

Figure 4. gp120 does not increase ACT mRNA levels in bigenic mice coexpressing GFAP-gp120 and GFAP-ACT fusion genes. (A) The effect of gp120 on the expression of the endogenous GFAP gene (top) or a GFAP-driven fusion gene (GFAP-ACT, bottom) was addressed in bigenic mice generated by crossing heterozygous GFAP-gp120 tg mice with heterozygous GFAP-ACT tg mice. Activation of the GFAP promoter (solid bar) in bigenic mice would result in transcription of

downstream elements and increase both GFAP and ACT mRNA levels, whereas a selective stabilization of GFAP mRNA would increase only GFAP mRNA levels (see text for further details). White boxes: GFAP exons; straight line: GFAP introns and 3 ' flanking region; $V$, SV40 late gene splice; jagged line, poly(A) signal/tail; elements not drawn to scale. The ACT cDNA was ligated into the modified GFAP exon 1 essentially as described (8). (B) RNA was extracted from brains of 4-mo-old non-tg (Non-tg), GFAP-ACT singly tg (ACT), GFAP-gp120 singly tg (gp120), and GFAP-ACT/GFAP-gp120 bigenic $(A C T+g p 120)$ mice and analyzed by RPA as described in Methods and Fig. 2. Two mice were analyzed per group. Note the increased GFAP mRNA levels in gp120 singly tg and gp120/ACT bigenic mice and the similar ACT mRNA levels in bigenic and ACT singly tg mice. PhosphorImager quantitation revealed no difference in ACT mRNA levels between bigenic and ACT single tg mice (not shown). In contrast, acute penetrating brain lesions, carried out as described (60), resulted in increased ACT mRNA levels (not shown), indicating that GFAP-driven expression of ACT was inducible by appropriate stimuli.

31). To further characterize the processes that mediate the gp120-induced stabilization of the GFAP message demonstrated in the current study, C6-gp120 cells were treated with reagents known to inhibit either PKC or PKA. PMA is a specific activator of PKC which, upon prolonged action, leads to a permanent translocation of the enzyme from cytosolic to particulate fractions and to a subsequent degradation of the enzyme, thereby inhibiting the PKC signal transduction pathway $(32,33)$. After $24 \mathrm{~h}$ of exposure to either PMA or the PKC inhibitors H7 or Calphostin C, C6-gp120 cells showed statistically significant reductions in GFAP mRNA levels and, over the range of concentrations tested, this effect correlated directly with the dose of inhibitors used (Fig. 5). In contrast, PKA inhibition using the specific PKA inhibitor HA1004 did not significantly affect GFAP mRNA levels found in C6-gp120 cells (Fig. 5). The activity of HA1004 was evaluated independently in C6-neo and C6-lacZ control cells in which it clearly decreased GFAP mRNA levels at $30 \mu \mathrm{M}$ (not shown).

Extracellular exposure to recombinant gp120 induced increases in steady state GFAP $m R N A$ levels in astrocytes. To determine whether intracellular expression of gp120 is required for the gp120-induced message stabilization, GFAP mRNA levels were compared in nontransfected C6 cells after exposure to either regular media or media containing recombinant gp120 at $100 \mathrm{pM}$ to $30 \mathrm{nM}$ final concentration. Compared with results obtained in mock-treated cells, $48 \mathrm{~h}$ of exposure to gp120 at $10 \mathrm{nM}$ final concentration effected a consistent increase in GFAP mRNA levels (15-27\% in four independent experiments; mean $\pm \mathrm{SEM}=21 \pm 2.5 \%, P<0.001$ by unpaired two-tailed Student's $t$ test). Higher gp120 concentrations did not result in further increases of GFAP mRNA levels.

Soluble gp120 induces $P K C$ redistribution in primary mouse astrocytes. To test whether extracellular exposure of glia to gp120 could result in PKC activation, primary astrocytes were established from neonatal non-tg mouse brains and incubated with different concentrations of recombinant gp120. Activation of PKC in individual primary astrocytes was assessed using double-immunolabeling against PKC and GFAP combined with laser scanning confocal microscopy. This method allows for the quantitation of increases in PKC immunoreactivity as well as redistribution of the enzyme after activation and has been used to demonstrate PKC activation (for review see reference 34; see Methods for details). Immunocytochemical analysis revealed that GFAP immunoreactive astrocytes in control cultures showed weak PKC immunoreactivity in their cell bodies and processes (Fig. $6 \mathrm{~A}$ ). Compared with these controls, gp120-treated astrocytes showed significant increases in both GFAP and PKC immunoreactivities as well as more prominent and elongated protoplasmic processes (Fig. 6, A and $B$ ). While mock-treated control cells showed diffuse PKC immunoreactivity, in gp120-stimulated astrocytes PKC immunoreactivity was concentrated along the cellular margins displaying a granular appearance (Fig. $6 A$ ). The PKC activator, PMA, induced similar changes in PKC and GFAP immunoreactivities (Fig. 6, $A$ and $B$ ). Similar effects of gp120 on PKC redistribution were obtained in experiments using C6 cells (data not shown).

PKC activity was increased in C6-gp120 cells as well as in gp120 tg brains. To further assess the participation of PKC in HIV-1-induced CNS alterations, PKC activity was quantitated directly both in vitro and in vivo. Levels of PKC activity in C6gp120 cells were elevated over those found in mock-transfected controls by 52 and $70 \%$ in two independent experiments. Furthermore, entire hemibrains of gp120 tg mice showed statistically significant increases in PKC activity compared with non-tg controls (Fig. $6 \mathrm{C}$ ). Notably, this effect was 


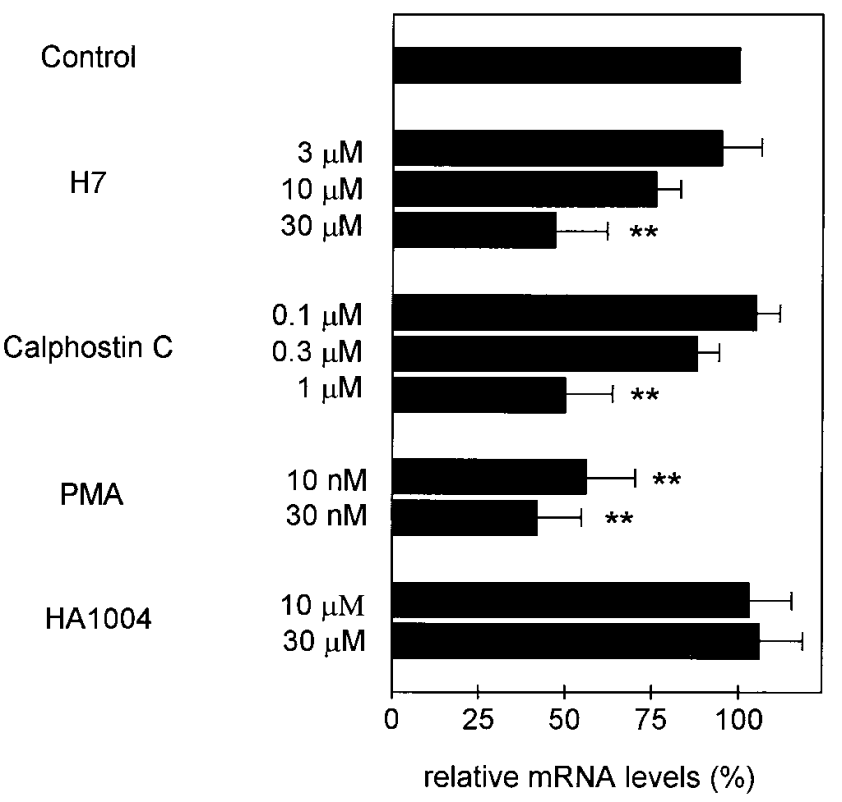

Figure 5. PKC inhibition decreased GFAP mRNA levels in C6-gp120 cells. RNA was isolated from C6-gp120 cells $24 \mathrm{~h}$ after the addition of vehicle alone (Control), or of the PKC inhibitors H7, Calphostin C, high concentrations of PMA, or the PKA inhibitor HA1004 (black bars, final concentrations in culture media indicated on the left). GFAP mRNA levels were compared by RPA and PhosphorImager quantitation using GAPDH signals to correct for differences in RNA content/loading. GFAP mRNA levels found in the control were arbitrarily defined as $100 \%$. Measurements obtained in the other samples were expressed in relation to this value. Bars represent means \pm SEM from 3 independent experiments. Only H7, Calphostin C, and high concentrations of PMA which inhibit PKC reduced GFAP mRNA levels significantly below control levels $(* * P<0.01$, by Dunnett's multiple comparisons test).

more prominent in tissue blocks of neocortices, hippocampi, and olfactory bulbs (Fig. $6 \mathrm{C}$ ), brain regions known to show the highest levels of transgene expression in gp120 mice (8).

Gliotic brains of humans with HIVE and of gp120 tg mice showed prominent increases in PKC immunoreactivity, whereas gliotic brains of humans with CMV encephalitis did not. To substantiate the pathogenetic relevance of the findings obtained in the in vivo and in vitro models described above, PKC expression levels were assessed immunohistochemically in human brain tissue obtained postmortem from AIDS patients with well-established HIVE or from uninfected controls (Fig. 7). Compared with controls, HIVE brains showed strongly increased PKC immunoreactivity in cells with astroglial morphology located in white matter (Fig. $7 \mathrm{~B}$ ), along the glial limitans (Fig. $7 C$ ) and, in severe cases, throughout all layers of the neocortex (not shown). Microdensitometric analysis of labeled brain sections revealed statistically significant increases in PKC immunoreactivity in the frontal cortex of HIVE cases and the fronto-parietal cortex of gp120 tg mice as compared with uninfected/non-tg controls (Fig. $7 \mathrm{D}$ ).

To evaluate the relative specificity of the association between HIVE and glial PKC upmodulation, gliotic brains from patients with HIVE or CMV encephalitis were compared with nongliotic brains from patients with CNS alterations using double-immunolabeling for PKC and GFAP and computeraided laser scanning confocal microscopy on postmortem spec-
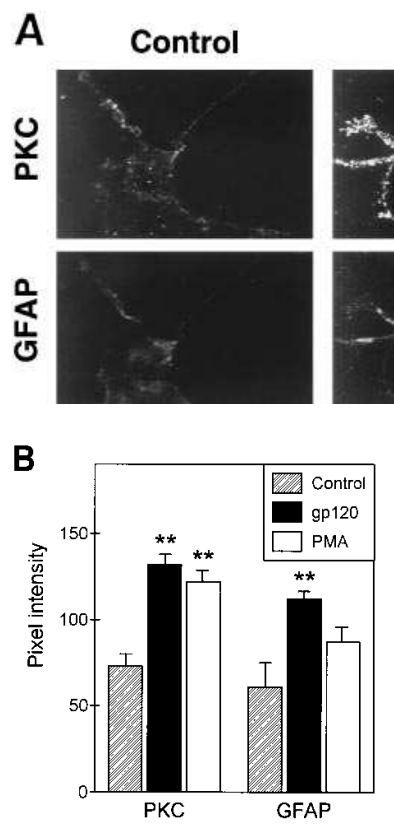

gp120
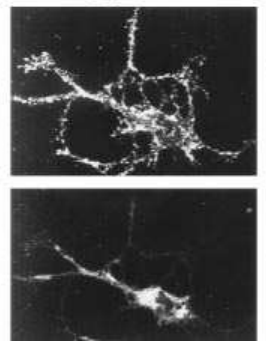

C

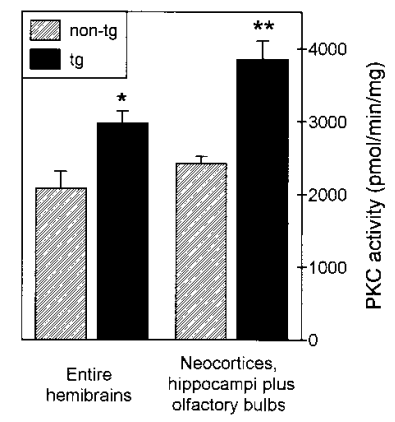

Figure 6. gp120 activates PKC in cultured primary astrocytes and increases PKC activity in brains of gp120 tg mice. Primary non-tg mouse astrocytes seeded onto glass coverslips were stimulated with $10 \mathrm{nM}$ recombinant gp120 or $100 \mathrm{nM}$ PMA for $1 \mathrm{~h}$ and subsequently stained with antibodies against PKC and GFAP as described in Methods. (A) Confocal microscopic images of astrocytes stained with antiPKC (top) or anti-GFAP (bottom) antibodies. Note the strong increase in and redistribution of immunoreactivities in gp120- and PMA-stimulated cells versus controls. (B) Semiquantitative assessment and statistical analysis of double-immunolabeled astrocytes revealed significant increases in PKC and GFAP immunoreactivities in gp120- and PMA-stimulated cells compared with mock-stimulated controls. Five fields per condition were analyzed in two independent experiments. Columns represent means $\pm \operatorname{SEM}(* * P<0.01$, by Dunnett's multiple comparisons test). (C) Entire hemibrains or tissue blocks including neocortices, hippocampi, and olfactory bulbs, brain regions showing the highest levels of transgene expression in gp120 tg mice (8), were obtained from gp120 tg and non-tg mice. PKC activity in these tissues was determined by enzyme assay as described in Methods. Results represent means \pm SEM (four mice per group). Compared with controls, gp120 tg mice showed significant increases in PKC activity $(* P<0.05 ; * * P<0.01$, by unpaired two-tailed Student's $t$ test).

imens as described in Methods. Although both HIVE and CMV encephalitis cases showed prominent increases in astroglial GFAP expression compared with controls, statistically significant increases in PKC immunoreactivity were only observed in HIVE cases (Fig. 8).

\section{Discussion}

To characterize molecular processes that could mediate the early and consistent development of astroglial alterations seen in HIV-1-infected humans, we combined analyses of in vitro and in vivo models with the immunohistochemical examination of postmortem tissue from human AIDS patients. A more complete understanding of HIV-1-associated astroglial alterations is needed since astrocytes provide crucial support for neurons and disturbances of astroglial functions could contrib- 


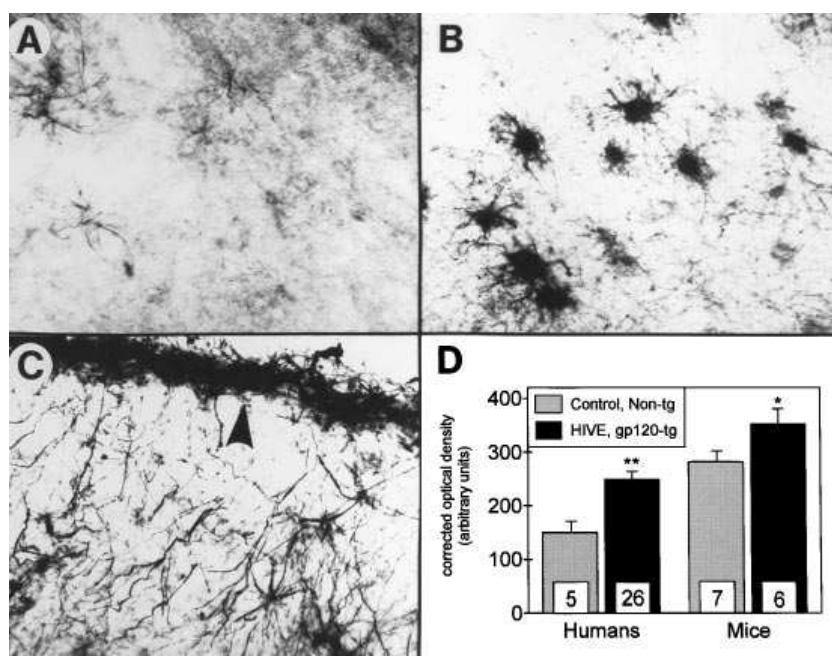

Figure 7. Increased PKC immunoreactivity in brains from humans with HIVE and from gp120 tg mice. Sections of human neocortices obtained postmortem from uninfected controls $(A)$ or patients with HIVE ( $B$ and $C$ ) and of murine neocortices from non-tg or gp120 tg mice were immunolabeled with a PKC-specific antibody as described in Methods. Cortical $(B)$ and subpial ( $C$, arrowhead) astrocytes of HIVE brains showed a marked increase in PKC expression compared with levels found in uninfected controls $(A)$. Quantitative microdensitometric analysis of labeled brain sections (three per case) revealed statistically significant increases in PKC immunoreactivity in both HIVE cases and gp120 tg mice compared with uninfected/non-tg controls $(D)$. Columns represent means \pm SEM. The number of cases analyzed is indicated at the bottom of each column. ${ }^{*} P<0.05$, $* * P<$ 0.02 , by unpaired two-tailed Student's $t$ test.

ute to the neuronal impairment that characterizes HIV-1-associated dementia and paralysis.

The astrocytosis found in gp120 tg mice and HIV-1-infected humans is associated with a prominent increase in GFAP expression. Notably, across different lines of gp120 tg mice the extent of astrocytosis correlated positively with steady state levels of gp120 and GFAP mRNA expression (Fig. 2). In contrast, tg mice expressing ACT in astrocytes from the GFAP promoter showed no significant alterations in steady state GFAP mRNA levels. Although prevention of gp120-induced neuronal damage by neuronal overexpression of amyloid precursor protein (APP) in gp120/APP bigenic mice significantly reduced the reactive astrocytosis in this model, the inhibition of astrocytosis was clearly less than complete (20). This raised the question of whether the residual astrocytosis in gp120/APP bigenic mice might be caused by more direct effects of gp120 on astrocytes. In general, it is likely that some detrimental factors have toxic effects on specific types of CNS cells, whereas others affect more than one type. The latter type of factor could induce a mixed reactive/primary astrocytosis that, in part, reflects the astroglial response to neuronal injury and, in part, is caused by direct effects on astrocytes. In combination with our previous observations $(8,20)$, the current study indicates that the astrocytosis induced in tg mice expressing HIV-1 gp120 is likely, in part, reactive and, in part, primary. While many factors may contribute to the astrocytosis seen in human HIV-1 infections (for reviews see references 14 and 15), the above findings strongly suggest that gp120 could play an important role in the pathogenesis of this CNS alteration also in humans.

To further dissect gp120 effects on GFAP gene expression in vitro and in vivo, C6 astrocytoma cells, which in several respects resemble astrocytes, as well as bigenic mice coexpressing gp120 with another GFAP-driven fusion gene were analyzed, respectively. Nuclear run-off assays of stably transfected C6-gp120 and C6-neo cells revealed that gp120 may induce a subtle increase in GFAP gene transcription but that this effect was unlikely to account for the substantial increase in GFAP mRNA levels found in C6-gp120 cells. The similar ACT mRNA levels in GFAP-ACT singly tg mice and ACT/gp120 bigenic mice further suggested that gp120 expression does not result in significant activation of transcription from the GFAP promoter in vivo. In contrast, measurements of GFAP mRNA decay rates after transcriptional inhibition in different stably

\section{A}
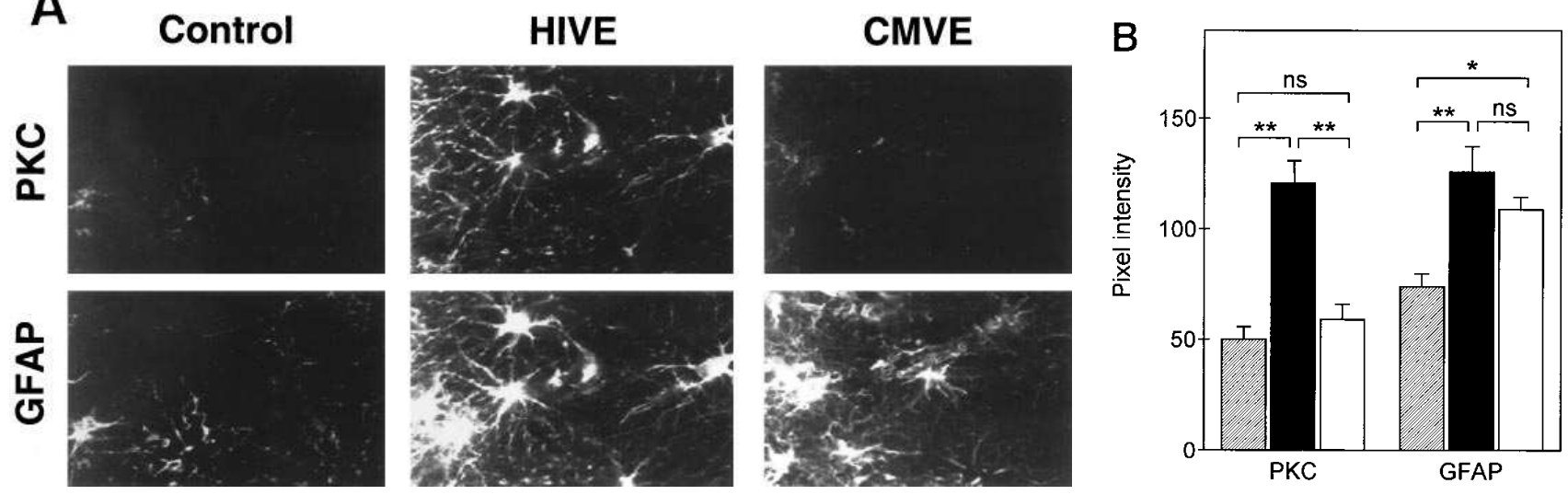

Figure 8. Comparison of PKC and GFAP expression in gliotic brains of humans with HIVE versus CMV encephalitis. Sections of human frontal cortex obtained postmortem from individuals with HIVE, CMV encephalitis $(C M V E)$, or controls without CNS alterations were double-immunolabeled with antibodies against PKC $(A$, top $)$ and GFAP $(A$, bottom $)$ and analyzed using laser scanning confocal microscopy as described in Methods. $(A)$ Note the prominent increase in PKC immunoreactivity in HIVE compared with CMVE and controls in spite of similar levels of GFAP immunostaining. (B) Semiquantitative assessment and statistical analysis of PKC and GFAP immunoreactivities in controls (gray columns), HIVE (black columns), and CMVE (white columns) cases. Note the significant increase in PKC immunoreactivity in HIVE versus controls and CMVE with no significant difference in GFAP immunoreactivity between HIVE and CMVE. Columns represent means \pm SEM from five patients with five fields analyzed per case ( $n s$, not significant; ${ }^{*} P<0.05 ;{ }^{*} P<0.01$, by Tukey-Kramer multiple comparisons test). 
transfected C6 cell lines demonstrated that gp120 induced a prominent stabilization of the GFAP message (Fig. 3).

Differences in degradation rates among mRNAs appear to contribute significantly to the control of gene expression in eukaryotes, particularly in higher organisms, and a variety of factors has been shown to influence mRNA stability (for reviews see references 35-37). The message-stabilizing effect of gp120 could involve direct interactions of gp120 with the GFAP message, or indirect effects of gp120 on factors that normally stabilize or destabilize this mRNA. In this study, steady state GFAP mRNA levels were also shown to increase in nontransfected C6 cells after extracellular exposure to recombinant gp120. Binding studies using flow cytometry have revealed that soluble gp120 can bind to the surface of C6 cells (WyssCoray, T., unpublished observation) as well as to other glialderived cell lines (38-40). While astrocytes do not appear to express $\mathrm{CD} 4$, a number of alternative receptors may be involved in the binding of gp120 to the surface of CNS cells (3841). In addition, primary rat cortical astrocytes can take up gp120 from their culture media and this process has been shown to induce alterations in astroglial cytokine production in vitro (42). Taken together, these findings have relevance to the HIV-1-infected human CNS in which astrocytes are likely to be exposed primarily to soluble gp120 shed into the extracellular milieu by infected macrophages $(2,43-45)$.

Because protein kinases are known to be involved in the posttranscriptional regulation of GFAP mRNA levels in astrocytoma cells and primary astrocytes $(21,31)$, we used protein kinase inhibitors to examine whether PKC- or PKA-dependent transduction pathways were involved in the gp120induced stabilization of the GFAP message in C6 cells. These experiments revealed that the increase in GFAP mRNA by gp120 was, at least partially, PKC dependent and independent of PKA activity (Fig. 5). We cannot rule out the involvement of other protein kinases in gp120-induced GFAP mRNA stabilization and astroglial alterations. gp120 expression was also found to increase total cellular PKC activity in brains of $\mathrm{tg}$ mice (Fig. 6 C) and in stably transfected C6-gp120 cells. The potential pathogenetic relevance of these findings was further supported by the demonstration of prominent increases in PKC immunoreactivity in postmortem brain tissue from patients with HIVE (Fig. 7). Gliotic brains of humans with CMV encephalitis failed to show such prominent PKC upmodulation (Fig. 8), indicating that mechanisms of astrocytosis and molecular profiles of astrocytes responding to different pathogens or forms of neural injury can differ.

Various studies have reported that HIV-1 and purified envelope proteins can induce signal transduction pathways leading to the activation of T cells, B cells, and monocytoid cells (for examples see references 46-48). Although several groups have addressed the effects of HIV-1 gp120 on signal transduction pathways in the CNS $(40,49-52)$, these studies did not determine whether the identified gp120 effects had any pathophysiological consequences in vitro or in vivo.

Our investigation indicates that HIV-1 gp120 can alter astroglial gene expression via activation of the PKC pathway and subsequent PKC-dependent message stabilization and provides evidence that this process results in pathological alterations of the CNS.

Activation of PKC is accompanied by the translocation of the enzyme from cytosolic to particulate fractions $(34,53,54)$. Here we demonstrate that recombinant gp120 can induce an increase and redistribution of PKC in primary cultured mouse astrocytes, consistent with PKC activation (32-34). Notably, the gp120-induced PKC alterations in these cultures were associated with an increase and redistribution of GFAP immunoreactivity (Fig. 6, $A$ and $B$ ). Intermediate filament proteins such as GFAP have been shown by several investigators to associate with PKC $(34,55-57)$, and it is possible that the association of activated PKC with GFAP induces a phosphorylation-dependent depolymerization of GFAP filaments (see reference 57). This might explain the relatively rapid increase in GFAP immunoreactivity induced by gp120 and PMA in primary astrocytes (Fig. $6 A$ ).

The PKC family consists of at least 11 isozymes that are activated by different processes and appear to fulfill diverse physiological functions in the CNS $(32,33,58,59)$. Studies are in progress to assess the relative contributions of these different PKC isoforms to alterations found in brains of gp120 tg mice and patients with AIDS.

\section{Acknowledgments}

We thank R. Messing for helpful comments on the manuscript and L. Feng and J.-C. de la Torre for advice on the analysis of mRNA stability and on nuclear run-offs.

This work was supported by National Institutes of Health grants MH47680 (L. Mucke), NS33056 (L. Mucke), and MH45294 (E. Masliah). L. Mucke was supported in part by a Harry Weaver Neuroscience Scholar Award from the National Multiple Sclerosis Society and $\mathrm{T}$. Wyss-Coray was supported in part by a fellowship award from the Swiss National Science Foundation (82AD-040163).

\section{References}

1. Price, R.W., and S.W. Perry. 1994. HIV, AIDS, and the Brain. Raven Press, New York.

2. Gendelman, H.E., S.A. Lipton, M. Tardieu, M.I. Bukrinsky, and H.S.L.M. Nottet. 1994. The neuropathogenesis of HIV-1 infection. J. Leukocyte Biol. 56:389-398.

3. Crowe, S.M., and R.S. Kornbluth. 1994. Overview of HIV interactions with macrophages and dendritic cells: the other infection in AIDS. J. Leukocyte Biol. 56:215-217.

4. Finkel, T.H., and N.K. Banda. 1994. Indirect mechanisms of HIV pathogenesis: how does HIV kill T cells? Curr. Opin. Immunol. 6:605-615.

5. Mosier, D., and H. Sieburg. 1994. Macrophage-tropic HIV: critical for AIDS pathogenesis. Immunol. Today. 15:332-339.

6. Stanley, L.C., R.E. Mrak, R.C. Woody, L.J. Perrot, S. Zhang, D.R. Marshak, S.J. Nelson, and W.S.T. Griffin. 1994. Glial cytokines as neuropathogenic factors in HIV infection: pathogenic similarities to Alzheimer's disease. J. Neuropathol. Exp. Neurol. 53:231-238.

7. Rosenberg, Z.F., and A.S. Fauci. 1990. Immunopathogenetic mechanisms of HIV infection: cytokine induction of HIV expression. Immunol. Today. 11:176-180.

8. Toggas, S.M., E. Masliah, E.M. Rockenstein, G.F. Rall, C.R. Abraham, and L. Mucke. 1994. Central nervous system damage produced by expression of HIV-1 coat protein gp120 in transgenic mice. Nature (Lond.). 367:188-193.

9. McArthur, J.C., P.S. Becker, J.E. Parisi, B. Trapp, O.A. Selnes, D.R. Cornblath, J. Balakrishnan, J.W. Griffin, and D. Price. 1989. Neuropathological changes in early HIV-1 dementia. Ann. Neurol. 26:681-684.

10. De La Monte, S.M., D.D. Ho, R.T. Schooley, M.S. Hirsch, and E.P.J. Richardson. 1987. Subacute encephalomyelitis of AIDS and its relation to HTLV-III infection. Neurology. 37:562-569.

11. Budka, H. 1991. Neuropathology of human immunodeficiency virus infection. Brain. Pathol. 1:163-175.

12. Lenhardt, T.M., M.A. Super, and C.A. Wiley. 1988. Neuropathological changes in an asymptomatic HIV seropositive man. Ann. Neurol. 23:209-210.

13. Norenberg, M.D. 1994. Astrocyte responses to CNS injury. J. Neuropathol. Exp. Neurol. 53:213-220.

14. Eddleston, M.P., and L. Mucke. 1993. Molecular profile of reactive astrocytes-implications for their role in neurologic disease. Neuroscience. 54:15-36.

15. Mucke, L., and E.M. Rockenstein. 1993. Prolonged delivery of transgene products to specific brain regions by migratory astrocyte grafts. Transgenics. 1:3-9. 
16. Rall, G.F., L. Mucke, M. Nerenberg, and M.B.A. Oldstone. 1994. A transgenic mouse model to assess the interaction of cytotoxic $\mathrm{T}$ lymphocytes with virally infected, class I MHC-expressing astrocytes. J. Neuroimmunol. 52: 61-68.

17. McConlogue, L., L. Paganini, L. Mucke, L. Refolo, M. Carman, I. Lieberburg, T. Oltersdorf, and J. Zhao. 1994. Transgenic mice expressing human Alzheimer's $\beta$-amyloid precursor protein produce high amounts of $\beta$-peptide. Neurobiol. Aging. 15:S12a. (Abstr.)

18. Johnson, W.B., M.D. Ruppe, E.M. Rockenstein, J. Price, V.P. Sarthy, L.C. Verderber, and L. Mucke. 1995. Indicator expression directed by regulatory sequences of the glial fibrillary acidic protein (GFAP) gene: in vivo comparison of distinct GFAP-lacZ transgenes. Glia. 13:174-184.

19. Abraham, C.R., B.L. Razzaboni, G. Papastoitsis, E. Picard, K. Kanemaru, B. Meckelein, and L. Mucke. 1992. Purification and cloning of brain proteases capable of degrading the $\beta$-amyloid precursor protein. Ann. NY Acad. Sci. 674:174-179.

20. Mucke, L., C.R. Abraham, M.D. Ruppe, E.M. Rockenstein, S.M. Toggas, M. Alford, and E. Masliah. 1995. Protection against HIV-1 gp120-induced brain damage by neuronal overexpression of amyloid protein precursor (APP). J. Exp. Med. 181:1551-1556.

21. Shafit-Zagardo, B., A. Kume-Iwaki, and J.E. Goldman. 1988. Astrocytes regulate GFAP mRNA levels by cyclic AMP and protein kinase C-dependent mechanisms. Glia. 1:346-354.

22. Bruns, R.F., F.D. Miller, R.L. Merriman, J.J. Howbert, W.F. Heath, E. Kobayashi, I. Takahashi, T. Tamaoki, and H. Nakano. 1991. Inhibition of protein kinase $\mathrm{C}$ by calphostin $\mathrm{C}$ is light-dependent. Biochem. Biophys. Res. Commun. 176:288-293.

23. Bordonaro, M., C.F. Saccomanno, and J.L. Nordstrom. 1994. An improved T1/A ribonuclease protection assay. BioTechniques. 16:428-430.

24. Kuo, C.F., and J.E. Darnell, Jr. 1989. Mouse glutamine synthetase is encoded by a single gene that can be expressed in a localized fashion. J. Mol. Biol. 208:45-56.

25. Greenberg, M.E., and E.B. Ziff. 1984. Stimulation of 3 T3 cells induces transcription of the c-fos proto-oncogene. Nature (Lond.). 311:433-438.

26. Thomas, T.P., R. Gopalakrishna, and W.B. Anderson. 1987. Hormoneand tumor promoter-induced activation or membrane association of protein kinase C in intact cells. Methods Enzymol. 141:399-411.

27. Yasuda, I., A. Kishimoto, S.I. Tanaka, M. Tominaga, A. Sakurai, and Y. Nishizuka. 1990. A synthetic peptide substrate for selective assay of protein kinase C. Biochem. Biophys. Res. Commun. 166:1220-1227.

28. Masliah, E., C.L. Achim, N. Ge, R. DeTeresa, R.D. Terry, and C.A. Wiley. 1992. Spectrum of human immunodeficiency virus-associated neocortical damage. Ann. Neurol. 32:321-329.

29. Masliah, E., K. Yoshida, S. Shimohama, F.H. Gage, and T. Saitoh. 1991. Differential expression of protein kinase $\mathrm{C}$ isozymes in rat glial cell cultures. Brain Res. 549:106-111.

30. Masliah, E., D.S. Iimoto, M. Mallory, T. Albright, L. Hansen, and T. Saitoh. 1992. Casein kinase alterations precedes tau accumulation in tangle formation. Am. J. Pathol. 140:263-268.

31. Sharma, N., K. Norman-O'Guin, and B. Shafit-Zagardo. 1991. Phorbol12-myristate-13-acetate (PMA) and inhibitors of protein kinase C alter glial fibrillary acidic protein (GFAP) mRNA levels. Glia. 4:572-579.

32. Huang, K.-P., and F.L. Huang. 1993. How is protein kinase $\mathrm{C}$ activated in CNS? Neurochem. Int. 22:417-433.

33. Nishizuka, Y. 1988. The molecular heterogeneity of protein kinase C and its implications for cellular regulation. Nature (Lond.). 334:661-665.

34. Mochly-Rosen, D. 1995. Localization of protein kinases by anchoring proteins: a theme in signal transduction. Science (Wash. DC). 268:247-250.

35. Atwater, J.A., R. Wisdom, and I.M. Verma. 1990. Regulated mRNA stability. Annu. Rev. Genet. 24:519-541.

36. Sachs, A.B. 1993. Messenger RNA degradation in eukaryotes. Cell. 74: 413-421.

37. Bernstein, P.L., D.J. Herrick, R.D. Prokipcak, and J. Ross. 1992. Control of c-myc mRNA half-life in vitro by a protein capable of binding to a coding region stability determinant. Genes \& Dev. 6:642-654.

38. Kozlowski, M.R., P. Sandler, P.F. Lin, and A. Watson. 1991. Brainderived cells contain a specific binding site for Gp120 which is not the CD4 antigen. Brain Res. 553:300-304.

39. Harouse, J.M., C. Kunsch, H.T. Hartle, M.A. Laughlin, J.A. Hoxie, B. Wigdahl, and F. Gonzalez-Scarano. 1989. CD4-independent infection of human neural cells by human immunodeficiency virus type 1. J. Virol. 63:2527-2533.

40. Schneider-Schaulies, J., S. Schneider-Schaulies, R. Brinkmann, P. Tas, M. Halbrugge, U. Walter, H.C. Holmes, and V. ter Meulen. 1992. HIV-1 gp120 receptor on CD4-negative brain cells activate a tyrosine kinase. Virology. 191: $765-772$.

41. Bhat, S., S.L. Spitalnik, F. Gonzalez-Scarano, and D.H. Silberberg 1991. Galactosyl ceramide or a derivative is an essential component of the neural receptor for human immunodeficiency virus type 1 envelope glycoprotein gp120. Proc. Natl. Acad. Sci. USA. 88:7131-7134.

42. Da Cunha, A., R.W. Jackson, and L. Vitkovic. 1995. HIV-1 alone is sufficient to stimulate production of TGF- $\beta 1$ in primary astrocytes. J. Neuroimmunol. 60:125-133.

43. Schneider, J., O. Kaaden, T.D. Copeland, S. Oroszlan, and G. Hunsmann. 1986. Shedding and interspecies type sero-reactivity of the envelop glycopolypeptide gp120 of the human immunodeficiency virus. J. Gen. Virol. 67: 2533-2538.

44. Tornatore, C., R. Chandra, J.R. Berger, and E.O. Major. 1994. HIV-1 infection of subcortical astrocytes in the pediatric central nervous system. Neurology. 44:481-487.

45. Saito, Y., L.R. Sharer, L.G. Epstein, J. Michaels, M. Mintz, M. Louder, K. Golding, T.A. Cvetkovich, and B.M. Blumberg. 1994. Overexpression of $n e f$ as a marker for restricted HIV-1 infection of astrocytes in postmortem pediatric central nervous tissues. Neurology. 44:474-481.

46. Gupta, S., S. Aggarwal, C. Kim, and S. Gollapudi. 1994. Human immunodeficiency virus-1 recombinant gp120 induces changes in protein kinase C isozymes—a preliminary report. Int. J. Immunopharmacol. 16:197-204.

47. Mohagheghpour, N., R. Chakrabarti, B.S. Stein, S.D. Gowda, and E.G. Engleman. 1991. Early activation events render T cells susceptible to HIV-1induced syncytia formation. Role of protein kinase C. J. Biol. Chem. 266:72337238.

48. Hofmann, B., P. Nishanian, T. Nguyen, P. Insixiengmay, and J.L. Fahey. 1993. Human immunodefiency virus proteins induce the inhibitory cAMP/protein kinase A pathway in normal lymphocytes. Proc. Natl. Acad. Sci. USA. 90: $6676-6680$.

49. Zorn, N.E., C.L. Weill, and D.H. Russell. 1990. The HIV protein, gp120, activates nuclear protein kinase $\mathrm{C}$ in nuclei from lymphocytes and brain. Biochem. Biophys. Res. Commun. 166:1133-1139.

50. Benos, D.J., B.H. Hahn, J.K. Bubien, S.K. Ghosh, N.A. Mashburn, M.A. Chaikin, G.M. Shaw, and E.N. Benveniste. 1994. Envelope glycoprotein gp120 of human immunodeficiency virus type 1 alters ion transport in astrocytes: implications for AIDS dementia complex. Proc. Natl. Acad. Sci. USA. 91: 494-498.

51. Savio, T., and G. Levi. 1993. Neurotoxicity of HIV coat protein gp120, NMDA receptors, and protein kinase C: a study with rat cerebellar granule cell cultures. J. Neurosci. Res. 34:265-272.

52. Bernardo, A., M. Patrizio, G. Levi, and T.C. Petrucci. 1994. Human immunodeficiency virus protein gp120 interferes with $\beta$-adrenergic receptormediated protein phosphorylation in cultured rat cortical astrocytes. Cell. Mol. Neurobiol. 14:159-174.

53. Kraft, A.S., and W.B. Anderson. 1983. Phorbol esters increase the amount of $\mathrm{Ca}^{2+}$, phospholipid-dependent protein kinase associated with plasma membrane. Nature (Lond.). 301:621-623.

54. Bazzi, M.D., and G.L. Nelsestuen. 1988. Properties of membraneinserted protein kinase C. Biochemistry. 27:7589-7593.

55. Harrison, B.C., and P.L. Mobley. 1992. Phosphorylation of glial fibrillary acidic protein and vimentin by cytoskeletal-associated intermediate filament protein kinase activity in astrocytes. J. Neurochem. 58:320-327.

56. Spudich, A., T. Meyer, and L. Stryer. 1992. Association of the $\beta$ isoform of protein kinase $\mathrm{C}$ with vimentin filaments. Cell. Motil. Cytoskeleton. 22:250 256

57. Inagaki, M., Y. Nakamura, M. Takeda, T. Nishimura, and N. Inagaki. 1994. Glial fibrillary acidic protein: dynamic property and regulation by phosphorylation. Brain. Pathol. 4:239-243.

58. Nishizuka, Y. 1995. Protein kinase $\mathrm{C}$ and lipid signaling for sustained cellular responses. FASEB. (Fed. Am. Soc. Exp. Biol.) J. 9:484-496.

59. Hug, H., and T.F. Sarre. 1993. Protein kinase C isoenzymes: divergence in signal transduction? Biochem. J. 291:329-343.

60. Mucke, L., M.B.A. Oldstone, J.C. Morris, and M.I. Nerenberg. 1991. Rapid activation of astrocyte-specific expression of GFAP-lacZ transgene by focal injury. New Biol. 3:465-474. 